\title{
Predictors of Surgical Intervention and Predicting Mortality in Patients with Spontaneous Intracerebral Hemorrhage
}

\author{
MOHAMED A. GHONEIM, M.D. and MOHAMED H. ALI, M.D. \\ The Department of Neurosurgery, Faculty of Medicine, Cairo University, Cairo, Egypt
}

\begin{abstract}
Background: Intracerebral Hemorrhage (ICH) is a major life threatening condition, for optimizing therapeutic efforts an early outcome assessment is essential.

Aim of Study: Recognize the factor affecting the outcome in patients with spontaneous intracerebral hematoma.

Patients and Methods: Data of cases had acute ICH between February 2016, and July 2018, were prospectively included. ICH score was applied, and we assessed outcome by the rate of mortality at 30-day and functional outcome at 6-month by Glasgow Outcome Scale (GOS).

Results: The study included 22 patients during its period. Rate of mortality at thirty day was $(40.9 \%) 9$ patients, and the incidence of patients had good functional outcome at 6 months was $(36.4 \%), 8$ patients with a Glasgow Outcome Scale (GOS) 4 to 5 at 6 months.

Conclusions: The Initial neurological state, (GCS score) pre-operative, with hematoma volume were a good predictors for detection the mortality rate after 30 days in case of the patients with primary spontaneous ICH. Patients with preoperative GCS below 9 and hematoma volume more than 42.6 had a great risk of bad short term outcome. The ICH score predict probably the mortality after 30 days and 6 month outcome (the ICH score on admission inversely related to outcome). Younger age and lobar ICH location, were important predictors of surgical intervention.
\end{abstract}

Key Words: Spontaneous intracerebral hematoma - Surgical treatment - Factors affecting outcome - Glasgow coma scale-Glasgow outcome scale.

\section{Introduction}

Spontaneous Intracerebral Hemorrhage (ICH) still presents challenges to neurosurgeons. Intracerebral hemorrhage is about $10-15 \%$ of a strokes, the good functional outcome with independency is obtained in only $20 \%$ of the cases with spontaneous ICH after 3 months of the onset of the intracerebral hemorrhage [1]. ICHs are subdivided into primary,

Correspondence to: Dr. Mohamed A. Ghoneim, The Department of Neurosurgery, Faculty of Medicine, Cairo University, Cairo, Egypt and secondary hematomas [2]. The primary type has a higher incidence than secondary type, account about $80 \%$ of all ICHs. The cause is destruction of the intracerebral small vessels either due to hypertension or amyloid angiopathy [3]. Secondary ICHs are due to trauma, neoplasms, arteriovenous malformations, aneurysms, or the hemorrhagic alteration of brain infarction. The clinical presentation of ICH depends on the site and volume of the hemorrhage, patient age and existence of other co morbidities [4]. Initial assessment of the outcome of these cases is deeply helpful for management optimization and avoidance of the over management that leads to a predicted bad outcome. There are a lot of scoring systems that can predict outcome in patients suffering from intracerebral haemorrhage. The ICH score (Table 1) was done to evaluate the rate of mortality after 30 days ranged from 0 to 6 [5]. We performed a study to analyze the outcome as rate of mortality after 30 days functional outcome after 6-months by Glasgow Outcome Scale (GOS) (Table 2).

Table (1): The ICH score [5].

\begin{tabular}{cc}
\hline Component & Point \\
\hline GCS score: & \\
$13-15$ & 0 \\
$5-12$ & 1 \\
$3-4$ & 2 \\
ICH volume, $\mathrm{cm}^{3}:$ & \\
$<30$ & 0 \\
$>=30$ & 1 \\
IVH: & \\
No & 0 \\
Yes & 1 \\
Infratentorial origin: & \\
No & 0 \\
Yes & 1 \\
Age, $y:$ & \\
$<80$ & 0 \\
$>=80$ & 1 \\
\hline Total & $0-6$ \\
\hline
\end{tabular}


Table (2): The Glasgow Outcome Scale (GOS) [6].

\begin{tabular}{cl}
\hline (GOS) score & Functional status \\
\hline 5 & $\begin{array}{l}\text { - Good recovery: Resumption of normal life } \\
\text { despite minor deficits }\end{array}$ \\
4 & - Moderate disability: Disabled but independ- \\
& ent; can work in sheltered setting \\
3 & - Severe disability: Conscious but disabled; \\
& dependent on others for daily support \\
2 & - Persistent vegetative state: Minimal respon- \\
& siveness \\
\hline
\end{tabular}

\section{Patients and Methods}

Data of patients with ICH from February 2016 to July 2018, were prospectively collected. ICH score was used, and we assessed Outcome by rate of mortality after 30 days and functional outcome after 6-months by Glasgow Outcome Scale (GOS), 22 cases suffering from spontaneous intracerebral hemorrhage with hematoma were selected the volume equals or more than $30 \mathrm{cc}$ in supratentorial and equals or more $4 \mathrm{~cm}$ infratentorial the Glasgow Coma Scale (GCS) equals or more than 6. We excluded patients with GCS less than 6 , absent of brain stem reflexes, and secondary hemorrhages were excluded.

\section{Results}

A total of 22 patients average (58.5 years) (range from 32 to 80 years). One patient (4.5\%) was 80 years of age. 14 males, (63.6\%) 8 female $(36.4 \%)$ average GCS score at the start was 9 (from 6 to 12). The data of the patients are collected in (Table 3). Arterial hypertension was present in $(81.8 \%)$ ( $\mathrm{n}=18$ patients), a smoking was present in 11 patients $(50 \%)$ a pre-operative therapy that affected hemostasis Warfarin use was taken in only 3 cases $(13.6 \%)$, while 8 patients $(36.4 \%)$ received aspirin (325mg per day). The most common location Figs. (1-3) of the bleeding was the basal ganglia and thalamic 17 patients $(77.3 \%)$ followed by, lobar 4 patients $(18.2 \%)$, post fossa $(4.5 \%, n=$ 1 patients). The ICH volume was 30-65 with average (42.6) $\mathrm{ml}$ relationship between conscious level and average volume of hematoma: GCS 9-12 average volume was $38.6 \mathrm{cc}$, and GCS 6-8 average volume was $48 \mathrm{cc}$. Intraventricular Hemorrhage (IVH) was detected in the first CT of 10 cases $(45.5 \%)$. The depth of the hematoma from the cortical surface was less than or equal $10 \mathrm{~mm}$ in 13 patients $(59.1 \%)$ and more than $10 \mathrm{~mm}$ in 9 patients $(40.9 \%)$.
The short term outcome at 30 days 9 patients $(40.9 \%)$ were dead. 5 patients $(22.7 \%)$ had good outcome (GOS 4 to 5), and 8 patients (36.4\%) had major disability (GOS 2 to 3 ). At 6 months 8 patients (36.4\%) had good outcome (GOS 4 to 5). 5 patients $(22.7 \%)$ alive with major impairment (GOS 2 to 3).

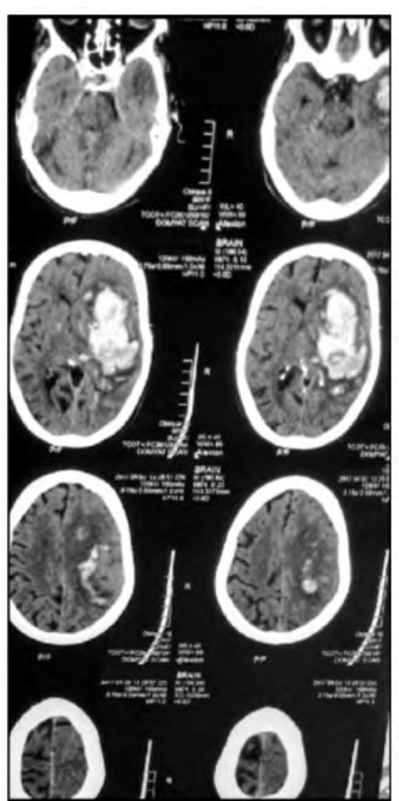

(A)

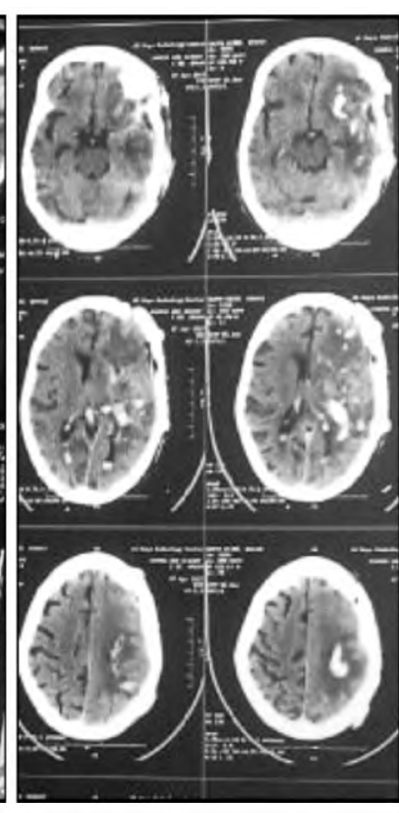

(B)
Fig. (1): Left basal ganglia hematoma in 80 years old female patient pre-operative (A) and post-operative (B).

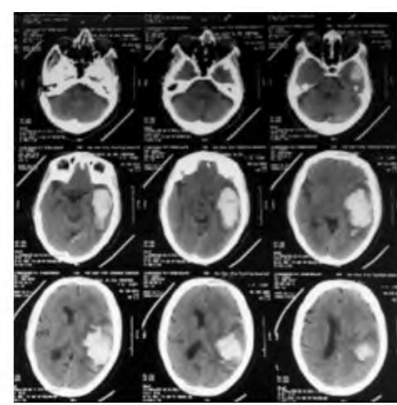

(A)

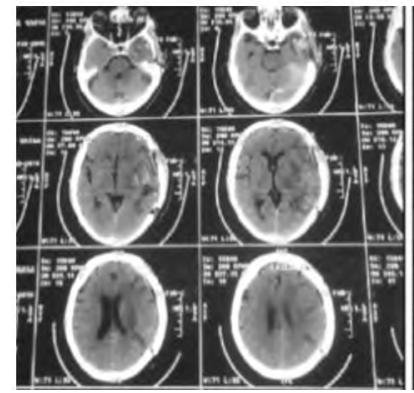

(C)

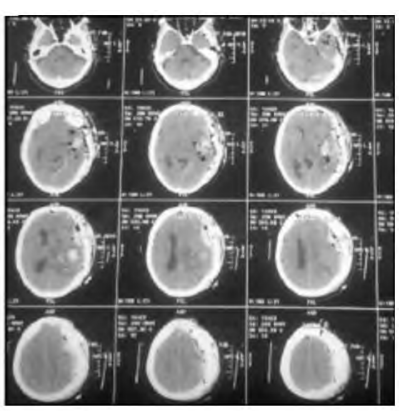

(B)

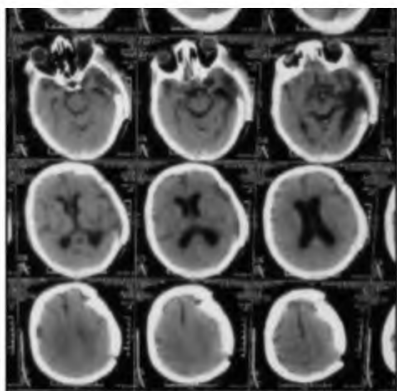

(D)
Fig. (2): Left temporal hematoma in 65 years old female patient pre-operative CT (A) Complicated by extradural hematoma and residual (B) Immediate evacuated (C), Follow-up after 6 month (D). 


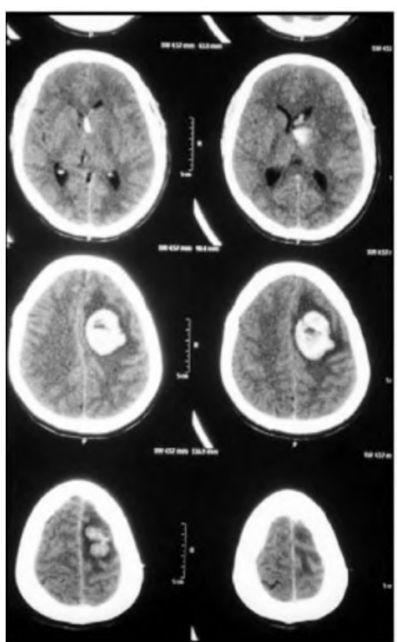

(A)

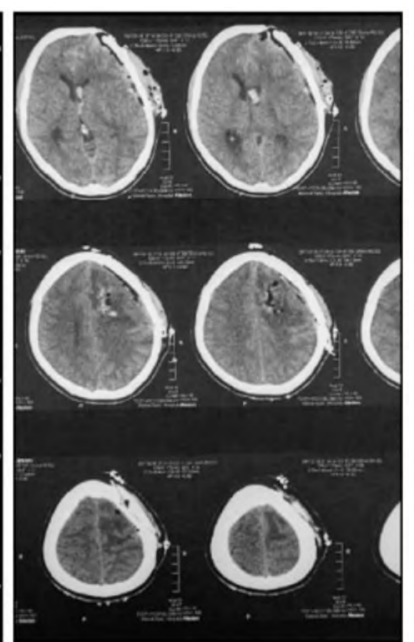

(B)

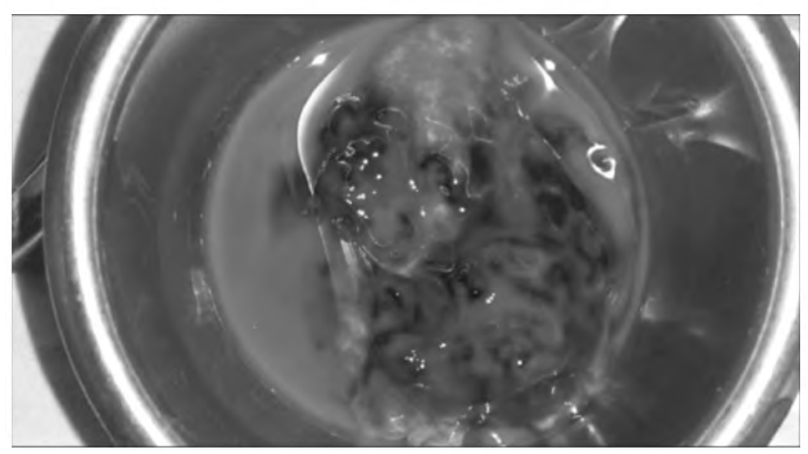

(C)

Fig. (3): Left frontal hematoma in female patient 32 years old on warfarin pre-operative $\mathrm{CT} \mathrm{A)} \mathrm{post-operative} \mathrm{CT}$ (B) hematoma (C).

Table (3): Characteristics of 22 patients of the study.

\begin{tabular}{|c|c|}
\hline Patients (n) & 22 \\
\hline Male/ & $14(63.6 \%) /$ \\
\hline female & $8 \quad(36.4 \%)$ \\
\hline Age (years) & Average 58.5 \\
\hline \multicolumn{2}{|l|}{ Glasgow Coma Scale (GCS) admission: } \\
\hline $\mathrm{GCS}=6-8, \mathrm{n}(\%)$ & $10(45.5 \%)$ \\
\hline $\mathrm{GCS}=9-12, \mathrm{n}(\%)$ & $12(54.5 \%)$ \\
\hline \multicolumn{2}{|l|}{ Comorbidities, $n(\%)$ : } \\
\hline Hypertension & $18(81.8 \%)$ \\
\hline Smoking & $11(50 \%)$ \\
\hline Use of anticoagulation & $3(13.6 \%)$ \\
\hline Use of antiplatelet & $8 \quad(36.4 \%)$ \\
\hline \multicolumn{2}{|l|}{ Location: } \\
\hline Basal ganglia and thalamic & $17(77.3 \%)$ \\
\hline Lobar & $4 \quad(18.2 \%)$ \\
\hline Post fossa & $1 \quad(4.5 \%)$ \\
\hline Intraventricular hemorrhage: & $10(45.5 \%)$ \\
\hline Intracerebral hemorrhage volume $(\mathrm{ml})$ & $30-65(42.6)$ \\
\hline Depth $\leq 10 \mathrm{~mm}$ & 13 \\
\hline$>10 \mathrm{~mm}$ & 9 \\
\hline
\end{tabular}

\section{Discussion}

Intracerebral Hemorrhage (ICH) is a major life threatening condition. The appropriate management is debatable and still a question of many studies with several treatment options $[7,8]$.

It is difficult to detect early prognosis causi ng persistent doubt about the "best initial treatment. From this point of view, we did our study to evaluate rate of mortality after 30 days and functional outcome after 6-months. As regard ICH score the 30 day mortality increased with increases in the scores' values. ICH score could predict outcome accurately (30-day mortality). Score 2 mortality was $25 \%$, score 3 mortality was $55.6 \%$, score 4 mortality was $100 \%$. In other study the rate of mortality at 30 days for the cases of spontaneous ICH ranging from 25 to $52 \%[9,10]$. In our study the short term outcome at 30 days. Table (4) 9 patients $(40.9 \%)$ were dead. 5 patients $(22.7 \%)$ had good outcome (GOS 4 to 5), and 8 patients (36.4\%) alive significant impairment (GOS 2 to 3). At 6 months 8 patients $(36.4 \%)$ had good outcome (GOS 4 to 5). 5 patients (22.7\%) alive with major disability (GOS 2 to 3 ). Corresponding to our data a study, done by Van Asch et al., with a functional outcome with the rate of independency ranging from 12 to $39 \%$ [11].

Our study showed increase 30 days mortality with increase of age of the patients, in patients less than 58.5 years mortality rate was $22.2 \%$, and in patients more than 58.5 years mortality rate was $77.8 \%$. Older people had more worse outcome [12]

Presence of co morbidities all patients died were hypertensive, $44.4 \%$ of patients used antiplatelet or anticoagulation died. The GCS score is a good predictor and reliable neurological assessment tool [13]. There is a strong relationship between GCS on admission (pre-operative) and 30 days mortality GCS below or equal 9 , the 30 days mortality rate was $88.9 \%$ (8/9). GCS more than 9 days mortality rate was $11.1 \% 1 / 9$. Relationship between hematoma volume and outcome 30 days mortality: Less than $42.6 C C 30$ days mortality was $2 / 11$ (18.2\%), more than 42.6CC 30 days mortality was $7 / 11(63.6 \%)$ so this study proved the neurological status at beginning (GCS) and the volume of ICH were strong predictors of outcome as proved in others $[\mathbf{5 , 9 , 1 1 , 1 3 , 1 4 ]}$. Lobar ICH had a better outcome [15].

In our study (infratentorial) one patient and died, basal ganglia and thalamic 7 patients from 17 patients died $(41.2 \%)$, lobar 1 patient from 4 patients died $(25 \%)$. The ICH Score is a good for 
prediction long-term functional outcome after spontaneous Intracerebral Hemorrhage (ICH) [5]. As regard our study six-month functional outcome 8 patients (36.4\%) had good outcome (GOS 4 to 5). 5 patients $(22.7 \%)$ were alive with major disability (GOS 2 to 3 ). With increasing points on the $\mathrm{ICH}$ scores there is a decreasing in functional outcome was found (Table 5).

Table (4): Predictors of death within 30 days.

\begin{tabular}{lc}
\hline & 30 days mortality \\
\hline Age (per year): & $2 / 922.2 \%$ \\
$\quad<58.5$ years & $7 / 977.8 \%$ \\
$>58.5$ years & M 6 F 3 \\
Sex & \\
GCS on admission: & $8 / 988.9 \%$ \\
$\quad<=9$ & $1 / 911.1 \%$ \\
$>9$ & \\
Comorbidities: & $9 / 9100 \%$ \\
$\quad$ Hypertension & $4 / 944.4 \%$ \\
Use of AP AC & \\
Imaging features: & $1 / 1100 \%$ \\
Location (infratentorial) & \\
Supratentorial & \\
Basal ganglia and thalamic & $7 / 1741.2 \%$ \\
Lobar & $1 / 425 \%$ \\
ICH volume: & \\
$\quad<42.6$ & $2 / 1118.2 \%$ \\
$>42.6$ & $7 / 1163.6 \%$ \\
\hline
\end{tabular}

Table (5): Relation between ICH score and 6 month functional outcome.

\begin{tabular}{lcccc}
\hline $\begin{array}{l}\text { ICH } \\
\text { score }\end{array}$ & Patients & $\begin{array}{c}\text { Died } \\
30 \text { day }\end{array}$ & $\begin{array}{c}\text { Good outcome } \\
\text { (GOS 4 to 5) } \\
6 \mathrm{~m}\end{array}$ & $\begin{array}{c}\text { Significant } \\
\text { impairment (GOS } \\
2 \text { to 3) 6m }\end{array}$ \\
\hline 2 & 12 & $3(25 \%)$ & $5(41.7 \%)$ & $4(33.3 \%)$ \\
3 & 9 & $5(55.6 \%)$ & $3(33.3 \%)$ & $1(11.1 \%)$ \\
4 & 1 & $1(100 \%)$ & & \\
\hline
\end{tabular}

\section{Conclusion:}

The initial neurological state, (GCS score) preoperative, with hematoma volume were a good predictors for detection the mortality rate after 30 days in case of the patients with primary spontaneous ICH. Patients with pre-operative GCS below 9 and hematoma volume more than 42.6 had a great risk of bad short term outcome. The ICH score predict probably the mortality after 30 days and 6 month outcome (the ICH score on admission inversely related to outcome). Younger age, and lobar ICH location, were important predictors of surgical intervention.

\section{References}

1- FLAHERTY M.L., HAVERBUSCH M., SEKAR P., KISSELA B., KLEINDORFER D., MOOMAW C.J., et al.: Long-term mortality after intracerebral hemorrhage. Neurology, 66: 1182-6, 2006.

2- SUTHERLAND G.R. and AUER R.N.: Primary intracerebral hemorrhage. J. Clin. Neurosci., 13: 511-7, 2006.

3- GREENBERG S.M., BRIGGS M.E., HYMAN B.T., KOKORIS G.J., TAKIS C., KANTER D.S., et al.: Apolipoprotein E epsilon 4 is associated with the presence and earlier onset of hemorrhage in cerebral amyloid angiopathy. Stroke, 27: 1333-7, 1996.

4- TOGHA M. and BAKHTAVAR K.: Factors associated with in-hospital mortality following intracerebral hemorrhage: A three-year study in Tehran, Iran. BMC Neurol., 4: 9,2004

5- HEMPHILL J.C. 3 rd, BONOVICH D.C., BESMERTIS L., MANLEY G.T. and JOHNSTON S.C.: The ICH score: A simple, reliable grading scale for intracerebral hemorrhage. Stroke, 32: 891-7, 2001.

6- JENNETT B. and BOND M.: Assessment of outcome after severe brain damage. Lancet, Mar. 1.1 (7905): 4804, 1975.

7- ANDERSON C.S., HUANG Y., WANG J.G., ARIMA H., NEAL B., PENG B., et al.: Intensive blood pressure reduction in acute cerebral haemorrhage trial (INTERACT): A randomised pilot trial. Lancet. Neurol., 7: 3919. 1, 2008.

8- MAYER S.A., BRUN N.C., BEGTRUP K., BRODERICK J., DAVIS S., DIRINGER M.N., et al.: Efficacy and safety of recombinant activated factor VII for acute intracerebral hemorrhage. N. Eng. J. Med., 358: 2127-37, 2008.

9- BHATIA R., SINGH H., SINGH S., PADMA M.V., PRASAD K., TRIPATHI M., et al.: A prospective study of inhospital mortality and discharge outcome in spontaneous intracerebral hemorrhage. Neurol. India, 61: 244-810, 2013.

10- SACCO S., MARINI C., TONI D., OLIVIERI L. and CAROLEI A.: Incidence and 10-year survival of intracerebral hemorrhage in a population-based registry. Stroke, 40: 394-9, 2009.

11-VAN ASCH C.J., LUITSE M.J., RINKEL G.J., VAN DER TWEEL I., ALGRA A. and KLIJN C.J.: Incidence, case fatality, and functional outcome of intracerebral haemorrhage over time, according to age, sex, and ethnic origin: A systematic review and meta-analysis. Lancet Neurol., 9: 167-76, 2010.

12- KARIN RÅDHOLM, HISATOMI ARIMA, RICHARD I. LINDLEY and JIGUANG WANG: Older age is a strong predictor for poor outcome in intracerebral haemorrhage: The INTERACT2 study Age and Ageing, Volume 44, Issue 3, May 2015, Pages 422-7, 2015.

13-NILSSON O.G., LINDGREN A., BRANDT L. and SAVELAND H.: Prediction of death in patients with primary intracerebral hemorrhage: A prospective study of a defined population. J. Neurosurg., 97: 531-6, 2002.

14- TAKAHASHI O., COOK E.F., NAKAMURA T., SAITO J., IKAWA F. and FUKUI T.: Risk stratification for in- 
hospital mortality in spontaneous intracerebral haemorrhage: A classification and regression tree analysis. Q.J.M., 99: 743 50. $27,2006$.

15- PALM F., HENSCHKE N., WOLF J., ZIMMER K.,
SAFER A., SCHRÖDER R.J., et al.: Intracerebral haemorrhage in a population-based stroke registry (LuSSt): Incidence, aetiology, functional outcome and mortality.

J. Neurol., 260: 2541-50. doi: 10.1007/s00415-013-7013-

0,2013

\section{تحديد التدخل الجراحى والتنبؤ بالنتائج فى حالات نزيف المغخ الآولى}

$$
\text { مقدمة: يمثل نزيف المخ تهديداً كبيراً على حياة المرضى. لتحديد العلاج المناسب يكن التقييم الآولى والتبؤ بالنتائج مهم. }
$$

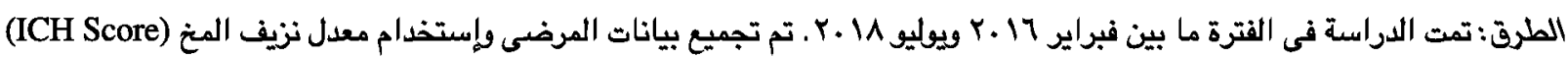

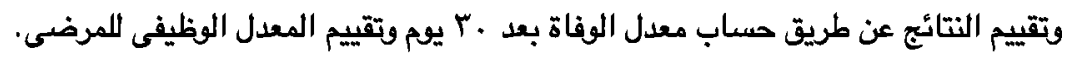

النتائج: تضمنت الدراسة بr مريض خلال تلك الفترة كان معدل الوفاة بعد •ب يوم حوالى 9 . ـ ع٪ ونسبة المرضى بمعدل وظيفى جيد بعد

$$
7
$$

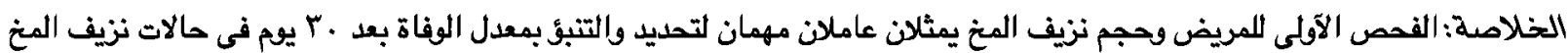

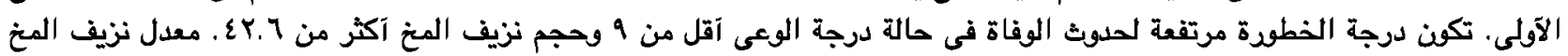
يمكنه التنبؤ بالنتائج (هناك علاقة عكسية ما بين معدل نزيف المخ الفح (ICH Score)

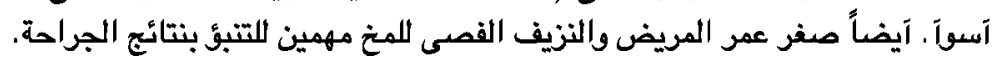

